\title{
The impact of the geographical location of residence and the type of community on alcohol consumption habits in Greece Konstantinos Katsigiannopoulos*1, Pandelis Pazarlis ${ }^{2}$, Ivan Cortinovis ${ }^{3}$, Georgios Papazisis ${ }^{2}$, Athanasios Milousis ${ }^{2}$, Pavlos Vasiliadis², Dimitrios Kakaridis ${ }^{2}$, Ioannis Levantakis ${ }^{2}$, Giovanni Casazza ${ }^{3}$ and Davide Mauri²
}

Address: ${ }^{1}$ Panhellenic Association for Continual Medical Research (PACMeR), Multicentric, Greece, 2 Panhellenic Association for Continual Medical Research (PACMeR) Section of Public-Health, Multicent, Greece and '3Istituto Di Statistica Medica E Biometria, Universita' Degli Studi Di Milano, Italy

* Corresponding author

from International Society on Brain and Behaviour: 2nd International Congress on Brain and Behaviour Thessaloniki, Greece. 17-20 November 2005

Published: 28 February 2006

Annals of General Psychiatry 2006, 5(SuppI I):S96 doi:10.1186/1744-859X-5-SI-S96

\section{Background}

Since alcohol-usage indicators have rapidly increased over the last decades, alcohol-abuse represents a major publichealth issue. Taking into consideration that changes in alcoholic beverages consumption have been associated with the shifting character of the Hellenic society (increased urbanization, industrialization and tourism), the purpose of the study is to reveal the impact of the geographical location of residence and the type of community on alcohol consumption habits.

\section{Materials and methods}

This study is part of a large ongoing survey on preventive and screening practices in Greece, which is organized by the PACMeR (Panhellenic Association for Continual Medical Research). For this project PACMeR physicians employed data coming from PACMeR trials' questionnaires. A sample of 5499 Hellenic individuals (2948 female, 2551 male, age range 21-97) entered the study and answered the questionnaires during a face-to-face interview. Safety data storing was assured by SESy_Europe Database, a 3-component database that it is dedicated to population-based cross-sectional surveys on prevention and screening activities. Alcohol consumption data was therefore abstracted from the database. Alcohol patterns were analysed using $\mathrm{x} 2$ test, likelihood ratio $\mathrm{x} 2$ test and Mantel-Haenszel test.

\section{Results}

The proportion of individuals consuming alcohol is notably higher in Crete Island (44.8\%) and the Aegean Islands $(41.9 \%)$ and lower in the Ionian Islands (38.5\%) and the mainland of Greece (33.6\%). Among men the proportion of alcohol usage is: Aegean Islands (71.4\%), Ionian Islands $(69.8 \%)$, Crete Island $(67.4 \%)$, and the mainland of Greece (53.2\%). The proportion of male ex-alcohol users is elevated in Crete (7.6\%) when compared with the rest of Greece (3.9\%). Among women the proportion alcohol of alcohol usage is slightly higher in Crete (20.1\%) and the Ionian Islands $(20.3 \%)$ than in the Aegean Islands (17.6\%) and the mainland of Greece (16.3\%). Residence (urban VS rural areas) don't play an important role in overall analysis $(\mathrm{p}=0.3037)$ and among males $(p=0.2040)$. When female individuals were considered a fair but statistically significant difference $(\mathrm{p}=$ 0.0389 ) in alcohol users (urban users $18.9 \%$ VS rural users $16.3 \%$ ) is found.

\section{Discussion}

People living in the islands and urban communities are at major risk for alcohol dependence. Targeted campaigns aiming to education and promotion of alcohol-free lifestyles should be intensified in these areas

\section{References}

I. San Jose B, Lagiou P, Chloptsios Y, Trichopoulou A: Sociodemographic correlates of abstinence and excessive drinking in the Greek population. Subst Use Misuse 200I, 36:463-475. 
2. Gual $\mathrm{A}$, Colom J: Why has alcohol consumption declined in countries of southern Europe? Addiction 1997, 92(Suppl I):2I-3I.

3. Madianos M, Gefou-Madianou D, Stefanis C: Patterns of alcohol consumption and related problems in the general population of Greece. Addiction 1995, 90:73-85.

4. Liakos A, Madianos M, Stefanis C: Alcohol consumption and rates of alcoholism in Greece. Drug Alcohol Depend 1980, 6:425-430.

Publish with Bio Med Central and every scientist can read your work free of charge

"BioMed Central will be the most significant development for disseminating the results of biomedical research in our lifetime. " Sir Paul Nurse, Cancer Research UK

Your research papers will be:

- available free of charge to the entire biomedical community

- peer reviewed and published immediately upon acceptance

- cited in PubMed and archived on PubMed Central

- yours - you keep the copyright 